\title{
Third-Space Endoscopy: Recent Updates
}

\author{
Zaheer Nabi ${ }^{1} \quad$ D Nageshwar Reddy ${ }^{1}$ \\ ${ }^{1}$ Department of Gastroenterology, Asian Institute of \\ Gastroenterology, Hyderabad, Telangana, India
}

\begin{abstract}
Address for correspondence Zaheer Nabi, MD, DNB, Department of Gastroenterology, Asian Institute of Gastroenterology, 6-3-661, Somajiguda, Hyderabad, Telangana, 500082, India (e-mail: zaheernabi1978@gmail.com).
\end{abstract}

\begin{abstract}
Keywords

- submucosal endoscopy

- achalasia

- gastroparesis

- Zenker's diverticulum

Third space or submucosal space is a potential space which on expansion allows the endoscopist to execute a multitude of therapeutic procedures for various gastrointestinal diseases like achalasia, subepithelial tumors, Zenker's diverticulum, and refractory gastroparesis. Third space was first utilized for performing endoscopic myotomy in cases with achalasia cardia about a decade ago. Since then, the field of submucosal endoscopy has witnessed an exponential growth. The present review focuses on recent advances in the field of third-space endoscopy. With regard to per-oral endoscopic myotomy (POEM) in achalasia cardia, several recent studies have evaluated the long-term outcomes of POEM, compared endoscopic myotomy with pneumatic dilatation (PD) and surgical myotomy, and evaluated the outcomes of short- versus long-esophageal myotomy. In addition, the utility of multiple dose antibiotic prophylaxis to prevent infections after POEM has been questioned. Overall, the results from these studies indicate that POEM is a durable treatment modality, equally effective to Heller's myotomy and superior to PD. With regard to gastric-POEM (G-POEM), recent studies suggest only modest efficacy in cases with refractory gastroparesis. Therefore, quality studies are required to identify predictors of response to optimize the outcomes of G-POEM in these cases. Another third-space endoscopy procedure that has gained popularity is endoscopic division of septum in cases with esophageal diverticula including Zenker's POEM and epiphrenic diverticula POEM (Z-POEM and D-POEM, respectively). The technique of diverticulotomy using the principles of submucosal endoscopy appears safe and effective in short term. Data on term outcomes are awaited and comparative trials with flexible endoscopic myotomy required. Per-rectal endoscopic myotomy (PREM) is the most recent addition to third space endoscopy procedures for the management of short-segment Hirschsprung's disease. Limited data suggest that PREM may be a promising alternative surgery in these cases. However, quality studies with long-term follow-up are required to validate the outcomes of PREM.
\end{abstract}

\section{Introduction}

Recent advances in therapeutic endoscopy have allowed minimally invasive management of many gastrointestinal

DOI https://doi.org/ $10.1055 / \mathrm{s}-0041-1739971$ ISSN 0976-5042
(GI) diseases. Third-space endoscopy or submucosal endoscopy is one such innovation that has amplified the therapeutic armamentarium for various GI diseases like achalasia, refractory gastroparesis, subepithelial lesions, esophageal (c) 2021. Society of Gastrointestinal Endoscopy of India.

This is an open access article published by Thieme under the terms of the Creative Commons Attribution-NonDerivative-NonCommercial-License, permitting copying and reproduction so long as the original work is given appropriate credit. Contents may not be used for commercial purposes, or adapted, remixed, transformed or built upon. (https://creativecommons.org/licenses/by-nc-nd/4.0/).

Thieme Medical and Scientific Publishers Pvt. Ltd. A-12, 2nd Floor, Sector 2, Noida-201301 UP, India 
diverticula, and others. Just over a decade old, the field of third-space endoscopy continues to evolve. As such, new pieces of information are being generated and published at a fairly rapid pace.

The purpose of this review is to provide recent updates in third-space endoscopy that may impact the routine clinical practice.

\section{Per-Oral Endoscopic Myotomy}

Long-Term Outcomes of Per-Oral Endoscopic Myotomy Multiple studies have confirmed the safety and efficacy of per-oral endoscopic myotomy (POEM) in achalasia at least during short-term follow-up. More recent studies suggest that the response to POEM may be durable as well. ${ }^{1-9}$ Campagna et al evaluated the outcomes of POEM in 100 patients who completed $\geq 4$ years of follow-up. ${ }^{6}$ Clinical success was recorded in $88 \%$ and objective evidence of gastroesophageal reflux disease (GERD) found in one-third of cases on long-term follow-up. In another large (610 patients), single-center study by Modayil and colleagues, clinical success at $\geq 5$ years was more than $90 \%$, confirming the durability of POEM in cases with achalasia cardia. ${ }^{8}$ Of note, reflux esophagitis (mostly mild) was detected in almost half of the patients in this study. Similar results have been provided in other studies where the clinical success has been reported in 80 to $95 \%$ of cases at a mean follow-up of $\geq 4$ to 5 years. . $^{3-5,7}$

\section{Short versus Standard Esophageal Myotomy}

POEM is an established treatment modality for achalasia and other allied esophageal motility disorders. Updated guidelines and position statements from various GI societies have incorporated POEM along with pneumatic dilatation (PD) and Heller's myotomy (HM) in the management algorithm for achalasia cardia. ${ }^{10-13}$ Since the initial description of POEM by Inoue and colleagues nearly a decade ago, the technique of POEM has largely remained unchanged. ${ }^{14}$ The standard technique of POEM involves a 8 - to $10-\mathrm{cm}$ long esophageal myotomy and 2 to $4 \mathrm{~cm}$ of gastric myotomy. While, a short gastric myotomy $(<1.5-2 \mathrm{~cm})$ has been shown to increase the risk of future relapses, ${ }^{15}$ the requirement of a long $(8-10 \mathrm{~cm})$ esophageal myotomy has been questioned in recent studies. ${ }^{16-20}$ Overall, three randomized trials and two retrospective studies have compared the outcomes of short versus standard or long esophageal myotomies in cases with idiopathic achalasia ( $\mathbf{- T a b l e ~} \mathbf{1}$ ). The results from these trials suggest that there is no significant difference in clinical efficacy between the two groups. Moreover, the procedure time was consistently shorter in the short myotomy group in all the studies. In a systematic review and meta-analysis including five studies with 474 patients, there was no difference in clinical success, symptomatic reflux, and overall adverse events between the two groups. However, the incidence of postoperative erosive esophagitis was lower in the short myotomy group (odds ratio $[\mathrm{OR}]=0.50,95 \%$ confidence interval [CI]: 0.24-1.03; $p=0.06) .{ }^{21}$

The results of these studies suggest that a short esophageal myotomy may be sufficient in cases with type-I and -II achalasia. However, caution is advised while extrapolating the results to type-III achalasia and other nonachalasia spastic esophageal motility disorders where long esophageal myotomies are recommended. ${ }^{22,23}$ Similarly, the impact of length of esophageal myotomy on the incidence of postoperative GERD needs further evaluation.

Table 1 Short versus standard esophageal myotomy in achalasia cardia

\begin{tabular}{|c|c|c|c|c|c|c|c|c|c|c|}
\hline $\begin{array}{l}\text { Study } \\
\text { (year) }\end{array}$ & $\begin{array}{l}\text { Study } \\
\text { design }\end{array}$ & $n$ (S vs. L) & $\begin{array}{l}\text { Myotomy } \\
\text { length } \\
(\mathrm{cm})\end{array}$ & $\begin{array}{l}\text { Procedure } \\
\text { duration } \\
\text { Mean (SD/ } \\
\text { range) }\end{array}$ & $\begin{array}{l}\text { Adverse } \\
\text { events } \\
\text { (\%) }\end{array}$ & $\begin{array}{l}\text { Erosive } \\
\text { esophagi- } \\
\text { tis (\%) }\end{array}$ & $\begin{array}{l}\text { Reflux } \\
\text { symptoms } \\
\text { (\%) }\end{array}$ & $\begin{array}{l}\mathrm{pH} \\
\text { GERD } \\
(\%)\end{array}$ & $\begin{array}{l}\text { Success } \\
\text { (\%) }\end{array}$ & $\begin{array}{l}\text { Follow-up } \\
\text { in months } \\
\text { (range) }\end{array}$ \\
\hline $\begin{array}{l}\text { Khashab } \\
\text { et al } \\
(2018)^{22}\end{array}$ & RCT & $\begin{array}{l}62 \\
58\end{array}$ & $\begin{array}{l}7 \text { (total) } \\
12\end{array}$ & $\begin{array}{l}43.6(17.0) \\
54.8(17.3)\end{array}$ & NR & \multicolumn{3}{|c|}{$\begin{array}{c}35 \text { vs. } 33.9 \% \text { (not known how } \\
\text { assessed) }\end{array}$} & $\begin{array}{l}100 \\
98.3\end{array}$ & $\begin{array}{l}6 \\
6\end{array}$ \\
\hline $\begin{array}{l}\text { Li et al } \\
(2019)^{17}\end{array}$ & $R$ & $\begin{array}{l}63 \\
63\end{array}$ & $\begin{array}{l}6-8 \\
\text { (tunnel) } \\
10-14\end{array}$ & $\begin{array}{l}39.5 \\
(21-74) \\
49.2 \\
(23-120)\end{array}$ & $\begin{array}{l}9.5 \\
33.3\end{array}$ & $\begin{array}{l}9.5 \\
12.7\end{array}$ & $\begin{array}{l}9.5 \\
12.7\end{array}$ & NR & $\begin{array}{l}98.2 \\
98.2\end{array}$ & $\begin{array}{l}20.1(6-48) \\
23.6(6-48)\end{array}$ \\
\hline $\begin{array}{l}\text { Huang } \\
\text { et al } \\
(2020)^{18}\end{array}$ & $R$ & $\begin{array}{l}36 \\
74\end{array}$ & $\begin{array}{l}\leq 7(\text { total }) \\
>7\end{array}$ & $\begin{array}{l}46.6(18.5) \\
62.1(25.2)\end{array}$ & $\begin{array}{l}8.3 \\
8.1\end{array}$ & $\begin{array}{l}2.8 \\
5.4\end{array}$ & NR & NR & $\begin{array}{l}94.4 \\
91.9\end{array}$ & $\begin{array}{l}26.8 \\
(8-54.3) \\
29.5 \\
(6-58.8)\end{array}$ \\
\hline $\begin{array}{l}\text { Gu et al } \\
(2021)^{19}\end{array}$ & RCT & $\begin{array}{l}46 \\
48\end{array}$ & $\begin{array}{l}\text { 3-4 (eso- } \\
\text { phageal) } \\
7-8\end{array}$ & $\begin{array}{l}31.2(15.3) \\
45.6(16.2)\end{array}$ & $\begin{array}{l}0 \\
2.2\end{array}$ & $\begin{array}{l}8.7 \\
14.6\end{array}$ & $\begin{array}{l}15.2 \\
22.9\end{array}$ & $\begin{array}{l}23.9 \\
43.8\end{array}$ & $\begin{array}{l}95.6 \\
93.8\end{array}$ & $\begin{array}{l}12 \\
12\end{array}$ \\
\hline $\begin{array}{l}\text { Nabi et al } \\
20(2021)\end{array}$ & RCT & $\begin{array}{l}34 \\
37\end{array}$ & $\begin{array}{l}\leq 3 \text { (esoph- } \\
\text { ageal) } \\
\geq 6\end{array}$ & $\begin{array}{l}44.03 \\
(13.78) \\
72.43 \\
(27.28)\end{array}$ & $\begin{array}{l}11.8 \\
10.8\end{array}$ & $\begin{array}{l}32.3 \\
48.6\end{array}$ & NR & $\begin{array}{l}25.9 \\
40\end{array}$ & $\begin{array}{l}93.5 \\
97\end{array}$ & $\begin{array}{l}12 \\
12\end{array}$ \\
\hline
\end{tabular}

Abbreviations: GERD, gastroesophageal reflux disease; L, long; NR, not reported; R, retrospective; RCT, randomized controlled trial; S, short; SD, standard deviation. 


\section{Per-Oral Endoscopic Myotomy versus Pneumatic Dilatation}

PD and Heller's myotomy (HM) have been the mainstay of treatment in achalasia cardia for several decades. Several randomized trials have concluded that the outcomes of graded dilatation are similar to $\mathrm{HM} .{ }^{24}$ With the introduction of POEM, the focus of recent research has diverted toward comparative evaluation of POEM with other treatment modalities. Several retrospective studies have concluded the superiority of POEM over PD. ${ }^{25-28}$ In a recent meta-analysis including 66 studies, clinical success with POEM was superior to PD at 12, 24, and 36 months (92.9, vs. $76.9 \% p=0.001 ; 90.6$ vs. $74.8 \%, p=0.004$; 88.4 vs. $72.2 \%, p=0.006$, respectively). In the only randomized trial published till date, 133 patients with achalasia were randomized to POEM or PD. ${ }^{29}$ The primary outcome of this study was clinical success (Eckardt's score $\leq 3$ ) at 2 years of follow-up. Clinical success was significantly higher in the POEM group (92 vs. 54\%). However, reflux esophagitis was also significantly higher in the POEM arm (41 vs. 7\%). Some of the limitations of this otherwise well-conducted randomized trial are worth mentioning. ${ }^{30} \mathrm{PD}$ was performed using 30 - to $35-\mathrm{mm}$ balloons instead of 30 - to $35-$ to $40-\mathrm{mm}$ balloons. Younger patients may require additional dilatation using a larger $(40 \mathrm{~mm})$ balloon for optimum response. Despite of lower clinical success, the barium emptying was intriguingly better in the PD arm, generating questions regarding the mechanisms of failure in the dilatation arm. Nevertheless, this randomized trial is the most robust comparison between the two modalities.

\section{Per-Oral Endoscopic Myotomy versus Heller's Myotomy}

Endoscopic and surgical myotomies have been compared one randomized study and several retrospective cohort studies. $^{31-41}$ Overall, the bulk of data suggest that both modalities provide with similar clinical success. A recent systematic review and meta-analysis comparing both the modalities concluded that POEM is more effective than laparoscopic Heller's myotomy (LHM) in relieving dysphagia in short term. ${ }^{42}$ The downside of POEM is higher reflux rates as compared with HM with fundoplication. ${ }^{42,43}$ A noteworthy flaw of the published systematic reviews is lack of randomized trials which impedes the generation of firm conclusions. Werner and colleagues conducted a noninferiority randomized trial including 221 patients. ${ }^{38}$ In this randomized trial, POEM was noninferior to LHM plus Dor's fundoplication in controlling symptoms of achalasia at 2 years (83 vs. $81.7 \%$ ). Gastroesophageal reflux was more common among patients who underwent POEM (44 vs. 29\%).

\section{Per-Oral Endoscopic Myotomy and Prophylactic Antibiotics}

Infectious complications are uncommon after POEM. Nevertheless, prophylactic antibiotics are commonly administered for a variable duration to prevent infection-related adverse events after POEM and other third-space endoscopy procedures. In the absence of quality evidence, considerable variations exist with regard to the duration of antibiotic prophylaxis. In a first, Repici and colleagues evaluated the role of prophylactic antibiotics in preventing infectious complications after POEM. In this study, the authors randomized 124 patients to single-dose antibiotic (intravenous [IV] cefazolin) or multiple-dose antibiotic (IV cefazolin on day 1 followed by oral amoxicillin/clavulanate for 3-days) groups. None of the patients developed fever in either groups. There was no difference between the groups with regard to systemic inflammation (white blood cells and C-reactive protein), immune response (interleukin [IL]-6, IL-1b, and tumor necrosis factor [TNF]-a), and microbial translocation (lipopolysaccharide binding protein and sCD14). Blood cultures were transiently positive in three patients including one in single-dose group and two in multiple-dose group. Overall, the results of this randomized trial question the utility of multiple doses of antibiotics to prevent infections after POEM. Besides this study, several ongoing trials are evaluating the role of prophylactic antibiotics in this setting (NCT03784365 and NCT03404739). If similar results are reproduced in these trials, single shot of antibiotic prophylaxis would allow reduction in the antibiotic usage in these cases.

\section{Gastric Per-Oral Endoscopic Myotomy}

Gastroparesis is a chronic debilitating disease characterized by a myriad of symptoms like nausea, vomiting, early satiety, abdominal discomfort, and others. In about a quarter of patients, gastroparesis may be refractory to nutritional and pharmacological therapies. The ideal management strategies are not clear in this subgroup. Per-oral endoscopic pyloromyotomy or gastric POEM (G-POEM) is a recent addition to the endoscopic armamentarium for the management of refractory gastroparesis. ${ }^{44-47}$ Overall, the pooled clinical response rate of G-POEM in the initial studies was 84\% (95\% CI: 77-89\%). ${ }^{48}$ However, the limitations of the initial studies include small sample size, retrospective design, and short follow-up periods. More recently, Vosoughi and colleagues evaluated the outcomes of G-POEM in a well-conducted, prospective, multicenter study. ${ }^{45}$ This study included 80 patients with refractory gastroparesis. The clinical success at 12 months was $56 \%$ (95\% CI: 44.8-66.7). The independent predictors of clinical success were baseline gastric cardinal symptom index (GCSI) score $>2.6$, baseline gastric retention $>20 \%$ at 4 hours and early response to G-POEM at 1 -month. In concordance to this trial, the clinical response in another multicenter study from France was 66\% at 1 -year. ${ }^{47}$ Overall, the results from the more recent studies highlight that G-POEM has a modest efficacy in cases with refractory gastroparesis. (Table 2)

In an attempt to address the suboptimal outcomes with the conventional G-POEM which involves single pyloromyotomy, Abdelfatah and colleagues evaluated the short-term outcomes with double pyloromyotomy. ${ }^{49}$ The clinical response was better in the double myotomy (86\%) group as compared with single myotomy (67\%). The shortcomings of 
this study is retrospective design and short follow-up duration (6 months).

In conclusion, the enthusiasm generated with initial studies which depicted a relatively high clinical success (80-85\%) has been somewhat dampened by some of the newer studies. The disparate outcomes in recent studies also underscore the need of quality trials with long-term follow-up and recognition of preoperative predictors of clinical response. Whether, Endo-functional lumen imaging probe (FLIP) will improve the preoperative prediction of clinical response remains to be seen in future studies.

\section{Per-Oral Endoscopic Myotomy for Esophageal Diverticula: Zenker's diverticulum and Epiphrenic diverticulum}

Esophageal diverticula (ED) are uncommon with a reported prevalence of 0.06 to $4 \%$. The three main types of ED include pharyngoesophageal diverticulum or the Zenker's diverticulum (ZD), epiphrenic diverticulum, and midesophageal or Rokitansky's diverticulum. The management of ZD has evolved from rigid endoscopic septotomy to flexible endoscopic division of cricopharyngeal septum. However, recurrences may occur in up to one-third patients on long-term follow-up. ${ }^{50}$ Incomplete septotomy has been proposed as one of the major reasons for symptomatic recurrence after flexible endoscopic septotomy. Recently, third-space endoscopy has been used for the management of ZD and termed as Z-POEM or submucosal tunneling endoscopic division of septum (STESD).51-56 Zenker's per-oral endoscopic myotomy (Z-POEM) allows for complete division of septum without undue risk of mucosal perforation. This in turn may reduce the risk of future recurrences. In recent studies, the clinical success with Z-POEM has been reported in more than $90 \%$ of cases - Table 3). ${ }^{51,52}$ In a multicenter comparative study, clinical success was comparable between Z-POEM and flexible septotomy ((92.7 vs. 86.7\%).53 Of note, long-term follow-up studies are lacking with regard to Z-POEM. In addition, randomized studies are required before concluding the superiority of Z-POEM over flexible endoscopic septotomy (Table 3).

Besides ZD, endoscopic division of septum has also been utilized in cases with epiphrenic diverticula and termed as diverticular per-oral endoscopic myotomy (D-POEM). ${ }^{57-60}$ The technique of D-POEM has been described in detail by the authors of this review. ${ }^{61}$ The standard technique of D-POEM involves division of diverticulum septum along with lower esophageal sphincter (LES) myotomy in cases with coexisting achalasia cardia. Alternatively, LES myotomy alone has also been found to be successful in relieving symptoms in cases with epiphrenic diverticula. ${ }^{59,62}$ The fact that majority

Table 2 Recent studies evaluating the outcomes of G-POEM in refractory gastroparesis

\begin{tabular}{|l|l|l|l|l|l|}
\hline Study (year) & $n$ & $\begin{array}{l}\text { Technical success } \\
(\%)\end{array}$ & $\begin{array}{l}\text { Clinical success } \\
(\%)\end{array}$ & Follow-up (mo) & $\begin{array}{l}\text { Adverse events } \\
\text { (\%) }\end{array}$ \\
\hline $\begin{array}{l}\text { Pioppo et al } \\
(2021)^{44}\end{array}$ & $\begin{array}{l}102 \text { (G-POEM:39, } \\
\text { surgery: 63) }\end{array}$ & $\begin{array}{l}100 \\
100\end{array}$ & $\begin{array}{l}92.3 \\
82.5\end{array}$ & $\begin{array}{l}5.5 \\
13\end{array}$ \\
\hline $\begin{array}{l}\text { Vosoughi et al } \\
(2021)^{45}\end{array}$ & 80 & 100 & 56 & 12 & 6 \\
\hline $\begin{array}{l}\text { Gregor et al } \\
(2021)^{46}\end{array}$ & 52 & 100 & $\begin{array}{l}6 \text { months: } 58 \\
12 \text { months: } 48\end{array}$ & 12 & 5.8 \\
\hline Ragi et al $(2021)^{47}$ & 76 & 99.2 & 65.8 & 12 & 6 \\
\hline
\end{tabular}

Abbreviation: G-POEM, gastric per-oral endoscopic myotomy.

Table 3 Recent studies depicting the outcome of Z-POEM in cases with Zenker's diverticulum

\begin{tabular}{|c|c|c|c|c|c|c|}
\hline Study (year) & Study design & $n$ & Size $(\mathrm{cm})$ & $\begin{array}{l}\text { Clinical } \\
\text { success (\%) }\end{array}$ & $\begin{array}{l}\text { Adverse } \\
\text { events (\%) }\end{array}$ & Follow-up \\
\hline $\begin{array}{l}\text { Yang et al } \\
(2020)^{51}\end{array}$ & $\mathrm{R}$, multicenter & 75 & 3.1 & 92 & 6.7 & 291 days (IQR: 104-436) \\
\hline $\begin{array}{l}\text { Elkholy et al } \\
(2021)^{52}\end{array}$ & R, multicenter & 24 & $4(2-7)$ & 95.8 & None & 10 months (IQR: 6-24) \\
\hline $\begin{array}{l}\text { Al Ghamdi et al } \\
(2021)^{53}\end{array}$ & $\mathrm{R}$, multicenter & $\begin{array}{l}245 \text { (Z-POEM: } \\
\text { 119, FES: } 86 \text {, rigid } \\
40)\end{array}$ & $\begin{array}{l}3.5,2.9 \\
3.6\end{array}$ & $\begin{array}{l}\text { Z-POEM: } 92.7 \text {, } \\
\text { FES: } 86.7 \text {, rigid: } \\
89.2\end{array}$ & $\begin{array}{l}\text { Z-POEM: } 16.8 \text {, } \\
\text { FES: } 2.3 \text {, rigid: } \\
30\end{array}$ & $282 \pm 300$ days \\
\hline $\begin{array}{l}\text { Budnicka et al } \\
(2021)^{54}\end{array}$ & $\mathrm{R}$, multicenter & 22 & 3 & 90.9 & 13.6 & 266 days (IQR: 213-306) \\
\hline $\begin{array}{l}\text { Kahaleh et al } \\
(2021)^{55}\end{array}$ & $\mathrm{R}$, multicenter & $\begin{array}{l}101 \text { (Z-POEM: 52, } \\
\text { septotomy: 49) }\end{array}$ & NR & $\begin{array}{l}\text { Z-POEM: } 92, \\
\text { septotomy: } 84\end{array}$ & $\begin{array}{l}\text { Z-POEM: 9.6, } \\
\text { septotomy: } 30.6\end{array}$ & $\begin{array}{l}3.4 \text { months } \\
7.9 \text { months }\end{array}$ \\
\hline $\begin{array}{l}\text { Sanaei et al } \\
(2021)^{56}\end{array}$ & $\mathrm{R}$, multicenter & $\begin{array}{l}32 \text { (previously } \\
\text { treated) }\end{array}$ & NR & 96.7 & 12.5 & 166 days (IQR: 39-566) \\
\hline
\end{tabular}

Abbreviations: IQR, interquartile range; NR, not reported; R, retrospective; FES, flexible endoscopic septotomy; Z-POEM, Zenker's per-oral endoscopic myotomy. 
of these diverticula have coexistent esophageal motility disorder with nonrelaxing LES supports this hypothesis. However, comparative trials are required between these two techniques.

\section{Per-Rectal Endoscopic Myotomy}

Hirschsprung's disease (HD) is a congenital motility disorder of intestine characterized by the absence of enteric ganglion cells. ${ }^{63} \mathrm{HD}$ usually involves distal colon (rectosigmoid, $80-85 \%$ ) and results in functional obstruction of large bowel. The standard of care for the management of HD is surgical resection of abnormally innervated segment of colon. Endorectal pull through and Duhamel's pull through procedures are the most commonly performed surgical procedures ${ }^{64}$ Recently, endoscopic management (utilizing the principles of third space endoscopy) has shown encouraging results in these cases. ${ }^{65-67}$ The technique of per-rectal endoscopic myotomy (PREM) as described by Bapaye and colleagues is discussed here. ${ }^{65}$ The first and foremost step involves mapping of aganglionic segment by analyzing serial biopsies obtained using the technique of band assisted endoscopic mucosal resection (EMR) described by Nabi and colleagues.68,69 Although band EMR can be performed along different orientations along the rectosigmoid colon, posterior site should be avoided to circumvent submucosal fibrosis during posterior myotomy. The actual procedure is performed under general anesthesia with the patient in a semi-jackknife position. Overall, the steps of PREM are similar to esophageal POEM for achalasia cardia and include submucosal lifting injection just inside the anorectal junction, mucosal incision, submucosal tunneling, and myotomy followed by closure of incision. It is important to carefully preserve external anal sphincter to avoid postoperative fecal incontinence.

Bapaye and colleagues initially reported PREM in an adult patient with short-segment HD. ${ }^{65}$ Subsequently, the authors reported the outcomes of PREM in nine patients with short-segment HD. ${ }^{67}$ The mean age of patients was 7.5 \pm 5.2 years and the average length of aganglionic segment was $6.3 \mathrm{~cm}$. The procedure was successfully performed in all the cases with a mean operative time of 96.1 minutes. At a median follow-up of 17 months (range: 9-58 months), improvement in stool frequency was noted in all the cases. Anal stenosis was reported in one patient. There were no other major adverse events. Of note, fecal incontinence was not reported in any case. There are several potential advantages of PREM. The procedure is essentially similar to esophageal POEM and therefore, should not be technically challenging for those already performing third-space endoscopy procedures. However, the data on outcomes of PREM are limited to case reports and small case series. Therefore, quality studies with larger sample size and longer follow-up are required before adopting PREM in cases with HD.

\section{Conclusion}

Third-space endoscopy is a field under progress. Multiple therapeutic endoscopic procedures have been unwrapped
Table 4 Summary of recent updates in third space endoscopy POEM in achalasia

1. Short and long esophageal myotomy provide with similar clinical success in type-I and -II achalasia

2. Single-dose antibiotic prophylaxis may be sufficient in cases undergoing POEM for achalasia

3. POEM is superior to pneumatic dilatation and equivalent to LHM with fundoplication. However, the incidence of GERD is higher after POEM

4. POEM is a durable treatment modality in achalasia with efficacy of $>90 \%$ at $\geq 4$-years

\section{G-POEM in refractory gastroparesis}

1. G-POEM has modest efficacy in cases with refractory gastroparesis

2. Double pyloromyotomy may potentially improve the outcomes with G-POEM. Randomized trials with long-term follow-up are required

POEM in esophageal diverticula

1. Z-POEM is a promising alternative to flexible endoscopic septotomy in Zenker's diverticulum

2. D-POEM is effective in cases with epiphrenic diverticula. Septotomy may not be required in cases with co-existing esophageal motility disorders. However, comparative trials are required

\section{PREM}

1. PREM appears promising in cases with short segment Hirschsprung's disease. Quality studies are required before PREM can be recommended in routine clinical practice

Abbreviations: GERD, gastroesophageal reflux disease; G-POEM, gastric per-oral endoscopic myotomy; PREM, per-rectal endoscopic myotomy; Z-POEM, Zenker's per-oral endoscopic myotomy; D-POEM, diverticular per-oral endoscopic myotomy.

under the umbrella of submucosal endoscopy. Ample data are available regarding the safety and efficacy of some of the third-space procedures like POEM for achalasia and submucosal tunneling endoscopic resection (STER) for subepithelial tumors. On the other hand, several gaps exist in the current understanding with regard to others like G-POEM and PREM. Recent studies indicate that G-POEM may not be as effective as initially thought in cases with refractory gastroparesis and therefore, it is paramount to evaluate the predictors for clinical efficacy. Similarly, more data are required before incorporating PREM in the management algorithm for HD. Z-POEM appears promising in cases with ZD. However, randomized comparison trials are required between the time tested flexible endoscopic myotomy and Z-POEM. - Table 4 summarizes recent developments in the field of third-space endoscopy.

\section{Conflict of Interest}

None declared.

\section{References}

1 Guo H, Yang H, Zhang X, et al. Long-term outcomes of peroral endoscopic myotomy for patients with achalasia: a retrospective single-center study. Dis Esophagus 2017;30(5):1-6

2 Li QL, Wu QN, Zhang XC, et al. Outcomes of per-oral endoscopic myotomy for treatment of esophageal achalasia with a median follow-up of 49 months. Gastrointest Endosc 2018;87(6):1405-1412.e3, e3 
3 Teitelbaum EN, Dunst CM, Reavis KM, et al. Clinical outcomes five years after POEM for treatment of primary esophageal motility disorders. Surg Endosc 2018;32(1):421-427

$4 \mathrm{He} \mathrm{C}$, Li M, Lu B, et al. Long-term efficacy of peroral endoscopic myotomy for patients with achalasia: outcomes with a median follow-up of 36 months. Dig Dis Sci 2019;64(3):803-810

5 Brewer Gutierrez OI, Moran RA, Familiari P, et al. Long-term outcomes of per-oral endoscopic myotomy in achalasia patients with a minimum follow-up of 4 years: a multicenter study. Endosc Int Open 2020;8(5):E650-E655

6 Campagna RAJ, Cirera A, Holmstrom AL, et al. Outcomes of 100 patients more than 4 years after POEM for achalasia. Ann Surg 2021;273(6):1135-1140

7 McKay SC, Dunst CM, Sharata AM, et al. POEM: clinical outcomes beyond 5 years. Surg Endosc 2021;35(10):5709-5716

8 Modayil RJ, Zhang X, Rothberg B, et al. Peroral endoscopic myotomy: 10-year outcomes from a large, single-center U.S. series with high follow-up completion and comprehensive analysis of long-term efficacy, safety, objective GERD, and endoscopic functional luminal assessment. Gastrointest Endosc 2021;94(5):930-942.

9 Onimaru $\mathrm{M}$, Inoue $\mathrm{H}$, Fujiyoshi $\mathrm{Y}$, et al. Long-term clinical results of per-oral endoscopic myotomy (POEM) for achalasia: First report of more than 10-year patient experience as assessed with a questionnaire-based survey. Endosc Int Open 2021;9(3):E409-E416

10 Jung HK, Hong SJ, Lee OY, et al. Korean Society of Neurogastroenterology and Motility. 2019 seoul consensus on esophageal achalasia guidelines. J Neurogastroenterol Motil 2020;26(2):180-203

11 Khashab MA, Vela MF, Thosani N, et al. ASGE guideline on the management of achalasia. Gastrointest Endosc 2020;91(2):213-227.e6, e6

12 Oude Nijhuis RAB, Zaninotto G, Roman S, et al. European guidelines on achalasia: United European Gastroenterology and European Society of Neurogastroenterology and Motility recommendations. United European Gastroenterol J 2020;8(1):13-33

13 Vaezi MF, Pandolfino JE, Yadlapati RH, Greer KB, Kavitt RT. ACG clinical guidelines: diagnosis and management of achalasia. Am J Gastroenterol 2020;115(9):1393-1411

14 Inoue $\mathrm{H}$, Minami $\mathrm{H}$, Kobayashi $\mathrm{Y}$, et al. Peroral endoscopic myotomy (POEM) for esophageal achalasia. Endoscopy 2010;42(4):265-271

15 Oelschlager BK, Chang L, Pellegrini CA. Improved outcome after extended gastric myotomy for achalasia. Arch Surg 2003;138(5):490-495, discussion 495-497

16 Tang XDZ, Gong W, Jiang B. PerOral endoscopic short versus long myotomy for the treatment of achalasia: a case-control study. Gastrointest Endosc 2015;5:AB117-AB118

17 Li L, Chai N, Linghu E, et al. . Safety and efficacy of using a short tunnel versus a standard tunnel for peroral endoscopic myotomy for Ling type IIc and III achalasia: a retrospective study. Surg Endosc 2019;33(5):1394-1402

18 Huang S, Ren Y, Peng W, et al. Peroral endoscopic shorter versus longer myotomy for the treatment of achalasia: a comparative retrospective study. Esophagus 2020;17(4):477-483

19 Gu L, Ouyang Z, Lv L, Liang C, Zhu H, Liu D. Safety and efficacy of peroral endoscopic myotomy with standard myotomy versus short myotomy for treatment-naïve patients with type II achalasia: a prospective randomized trial. Gastrointest Endosc 2021;93(6):1304-1312

20 Nabi Z, Ramchandani M, Sayyed M, et al. Comparison of short versus long esophageal myotomy in cases with idiopathic achalasia: a randomized controlled trial. J Neurogastroenterol Motil 2021;27(1):63-70
21 Chandan S, Facciorusso A, Khan SR, et al. Short versus standard esophageal myotomy in achalasia patients: a systematic review and meta-analysis of comparative studies. Endosc Int Open 2021;09:E1246-E1254

22 Khashab MA, Familiari P, Draganov PV, et al. Peroral endoscopic myotomy is effective and safe in non-achalasia esophageal motility disorders: an international multicenter study. Endosc Int Open 2018;6(8):E1031-E1036

23 Nabi Z, Chavan R, Ramchandani M, et al. Long-term outcomes of per-oral endoscopic myotomy in spastic esophageal motility disorders: a large, single-center study. J Clin Gastroenterol 2021;55(7):594-601

24 Boeckxstaens GE, Annese V, des Varannes SB; European Achalasia Trial Investigators, et al. Pneumatic dilation versus laparoscopic Heller's myotomy for idiopathic achalasia. N Engl J Med 2011;364(19):1807-1816

25 Meng F, Li P, Wang Y, et al. Peroral endoscopic myotomy compared with pneumatic dilation for newly diagnosed achalasia. Surg Endosc 2017;31(11):4665-4672

26 Andolfi C, Fisichella PM. Meta-analysis of clinical outcome after treatment for achalasia based on manometric subtypes. Br J Surg 2019;106(4):332-341

27 Kim GH, Jung KW, Jung HY, et al. Superior clinical outcomes of peroral endoscopic myotomy compared with balloon dilation in all achalasia subtypes. J Gastroenterol Hepatol 2019;34(4):659-665

28 Zheng Z, Zhao C, Su S, et al. Peroral endoscopic myotomy versus pneumatic dilation - result from a retrospective study with 1-year follow-up. Z Gastroenterol 2019;57(3):304-311

29 Ponds FA, Fockens P, Lei A, et al. Effect of peroral endoscopic myotomy vs pneumatic dilation on symptom severity and treatment outcomes among treatment-naive patients with achalasia: a randomized clinical trial. JAMA 2019;322(2):134-144

30 Yadlapati R, Gupta S. Peroral endoscopic myotomy versus pneumatic dilation in achalasia: dissecting the randomized controlled trial. Gastroenterology 2020;158(1):276-277

31 Bhayani NH, Kurian AA, Dunst CM, Sharata AM, Rieder E, Swanstrom LL. A comparative study on comprehensive, objective outcomes of laparoscopic Heller myotomy with per-oral endoscopic myotomy (POEM) for achalasia. Ann Surg 2014;259(6):1098-1103

32 Kumagai K, Tsai JA, Thorell A, Lundell L, Håkanson B. Per-oral endoscopic myotomy for achalasia. Are results comparable to laparoscopic Heller myotomy? Scand J Gastroenterol 2015;50(5):505-512

33 Chan SM, Wu JC, Teoh AY, et al. Comparison of early outcomes and quality of life after laparoscopic Heller's cardiomyotomy to peroral endoscopic myotomy for treatment of achalasia. Dig Endosc 2016;28(1):27-32

34 Schneider AM, Louie BE, Warren HF, Farivar AS, Schembre DB, Aye RW. A matched comparison of per oral endoscopic myotomy to laparoscopic Heller myotomy in the treatment of achalasia. J Gastrointest Surg 2016;20(11):1789-1796

35 Docimo S Jr., Mathew A, Shope AJ, Winder JS, Haluck RS, Pauli EM. Reduced postoperative pain scores and narcotic use favor per-oral endoscopic myotomy over laparoscopic Heller myotomy. Surg Endosc 2017;31(2):795-800

36 Hanna AN, Datta J, Ginzberg S, Dasher K, Ginsberg GG, Dempsey DT. Laparoscopic Heller myotomy vs per oral endoscopic myotomy: patient-reported outcomes at a single institution. J Am Coll Surg 2018;226(4):465-472.e1, e1

37 Shea GE, Johnson MK, Venkatesh M, et al. . Long-term dysphagia resolution following POEM versus Heller myotomy for achalasia patients. Surg Endosc 2020;34(4):1704-1711

38 Werner YB, Hakanson B, Martinek J, et al. Endoscopic or surgical myotomy in patients with idiopathic achalasia. N Engl J Med 2019;381(23):2219-2229 
39 Wirsching A, Boshier PR, Klevebro F, et al. Comparison of costs and short-term clinical outcomes of per-oral endoscopic myotomy and laparoscopic Heller myotomy. Am J Surg 2019;218(4):706-711

40 Costantini A, Familiari P, Costantini M, et al. Poem versus laparoscopic Heller myotomy in the treatment of esophageal achalasia: a case-control study from two high volume centers using the propensity score. J Gastrointest Surg 2020;24(3):505-515

41 Podboy AJ, Hwang JH, Rivas $\mathrm{H}$, et al. Long-term outcomes of per-oral endoscopic myotomy compared to laparoscopic Heller myotomy for achalasia: a single-center experience. Surg Endosc 2021;35(2):792-801

42 Schlottmann F, Luckett DJ, Fine J, Shaheen NJ, Patti MG. Laparoscopic Heller myotomy versus peroral endoscopic myotomy (POEM) for achalasia: a systematic review and meta-analysis. Ann Surg 2018;267(3):451-460

43 Repici A, Fuccio L, Maselli R, et al. GERD after per-oral endoscopic myotomy as compared with Heller's myotomy with fundoplication: a systematic review with meta-analysis. Gastrointest Endosc 2018;87(4):934-943.e18, e18

44 Pioppo L, Reja D, Gaidhane M, et al. Gastric per-oral endoscopic myotomy versus pyloromyotomy for gastroparesis: an international comparative study. J Gastroenterol Hepatol 2021;36(11):3177-3182.

45 Vosoughi K, Ichkhanian Y, Benias P, et al. Gastric per-oral endoscopic myotomy (G-POEM) for refractory gastroparesis: results from an international prospective trial. Gut 2021;(e-pub ahead of print). doi:10.1136/gutjnl-2020-322756

46 Gregor L, Wo J, DeWitt J, et al. Gastric peroral endoscopic myotomy for the treatment of refractory gastroparesis: a prospective single-center experience with mid-term follow-up (with video. Gastrointest Endosc 2021;94(1):35-44

47 Ragi O, Jacques J, Branche J, et al. One-year results of gastric peroral endoscopic myotomy for refractory gastroparesis: a French multicenter study. Endoscopy 2021;53(5):480-490

48 Li P, Ma B, Gong S, Zhang X, Li W. Gastric per-oral endoscopic myotomy for refractory gastroparesis: a meta-analysis. J Gastrointest Surg 2021;25(5):1108-1116

49 Abdelfatah MM, Li B, Kapil N, et al. Short-term outcomes of double versus single pyloromyotomy at peroral endoscopic pyloromyotomy in the treatment of gastroparesis (with video. Gastrointest Endosc 2020;92(3):603-609

50 Repici A, Cappello A, Spadaccini M, et al. Cap-assisted endoscopic septotomy of Zenker's diverticulum: early and long-term outcomes. Am J Gastroenterol 2021;116(9):1853-1858

51 Yang J, Novak S, Ujiki M, et al. . An international study on the use of peroral endoscopic myotomy in the management of Zenker's diverticulum. Gastrointest Endosc 2020;91(1):163-168

52 Elkholy S, El-Sherbiny M, Delano-Alonso R, et al. Peroral endoscopic myotomy as treatment for Zenker's diverticulum (Z-POEM): a multi-center international study. Esophagus 2021;18(3):693-699

53 Al Ghamdi SS, Farha J, Moran RA, et al. Zenker's peroral endoscopic myotomy, or flexible or rigid septotomy for Zenker's diverticulum: a multicenter retrospective comparison. Endoscopy 2021;(e-pub ahead of print). doi:10.1055/a-1518-7223

54 Budnicka A, Januszewicz W, Białek AB, Spychalski M, Reguła J, Kaminski MF. Peroral endoscopic myotomy in the management of Zenker's diverticulum: a retrospective multicenter study. J Clin Med 2021;10(2):10

55 Kahaleh M, Mahpour NY, Tyberg A, et al. Per oral endoscopic myotomy for Zenker's diverticulum: a novel and superior technique compared with septotomy? J Clin Gastroenterol 2021;(e-pub ahead of print). doi:10.1097/ MCG.0000000000001579

56 Sanaei O, Ichkhanian Y, Mondragón OVH, et al. Impact of prior treatment on feasibility and outcomes of Zenker's peroral endoscopic myotomy (Z-POEM). Endoscopy 2021;53(7):722-726

57 Yang J, Zeng X, Yuan X, et al. An international study on the use of peroral endoscopic myotomy (POEM) in the management of esophageal diverticula: the first multicenter D-POEM experience. Endoscopy 2019;51(4):346-349

58 Basile P, Gonzalez JM, Le Mouel JP, Irarrazaval R, Caillo L, Barthet M. Per-oral endoscopic myotomy with septotomy for the treatment of distal esophageal diverticula (D-POEM). Surg Endosc 2020;34(5):2321-2325

59 Demeter $M$, Ďuriček $M$, Vorčák $M$, Hyrdel R, Kunda R, Bánovčin P. S-POEM in treatment of achalasia and esophageal epiphrenic diverticula - single center experience. Scand J Gastroenterol 2020;55(4):509-514

60 Nabi Z, Chavan R, Asif S, et al. Per-oral endoscopic myotomy with division of septum (D-POEM) in epiphrenic esophageal diverticula: outcomes at a median follow-up of two years. Dysphagia 2021;(e-pub ahead of print). doi:10.1007/s00455-021-10339-8

61 Nabi Z, Ramchandani M, Darisetty S, Kotla R, Reddy DN. Per-oral endoscopic myotomy with endoscopic septum division in a case of achalasia with large epiphrenic diverticulum. VideoGIE 2018;4(1):14-16

62 Kinoshita M, Tanaka S, Kawara F, et al. Peroral endoscopic myotomy alone is effective for esophageal motility disorders and esophageal epiphrenic diverticulum: a retrospective single-center study. Surg Endosc 2020;34(12):5447-5454

63 Kessmann J. Hirschsprung's disease: diagnosis and management. Am Fam Physician 2006;74(8):1319-1322

64 Kyrklund K, Sloots CEJ, de Blaauw I, et al. ERNICA guidelines for the management of rectosigmoid Hirschsprung's disease. Orphanet J Rare Dis 2020;15(1):164

65 Bapaye A, Wagholikar G, Jog S, et al. Per rectal endoscopic myotomy for the treatment of adult Hirschsprung's disease: First human case (with video. Dig Endosc 2016;28(6):680-684

66 Bapaye A, Bharadwaj T, Mahadik M, et al. . Per-rectal endoscopic myotomy (PREM) for pediatric Hirschsprung's disease. Endoscopy 2018;50(6):644-645

67 Bapaye A, Dashatwar P, Biradar V, Biradar S, Pujari R. Initial experience with per-rectal endoscopic myotomy for Hirschsprung's disease: medium and long term outcomes of the first case series of a novel third-space endoscopy procedure. Endoscopy 2020;(e-pub ahead of print). doi:10.1055/a-1332-6902

68 Nabi Z, Chavan R, Shava U, Sekharan A, Reddy DN. A novel endoscopic technique to obtain rectal biopsy specimens in children with suspected Hirschsprung's disease. VideoGIE 2018;3(5):157-158

69 Nabi Z, Shava U, Sekharan A, Nageshwar Reddy D. Diagnosis of Hirschsprung's disease in children: Preliminary evaluation of a novel endoscopic technique for rectal biopsy. JGH Open 2018;2(6):322-326 